\section{Progress of CNA to become the Spanish facility for combined irradiation testing in aerospace}

\author{
Y. Morilla1, P. Martín-Holgado', A. Romero'1, J.A. Labrador'1, B. Fernández', J. Praena², \\ A. Lindoso ${ }^{3}$, Mario García-Valderas ${ }^{3}$, M. Peña-Fernández ${ }^{3}$ and L. Entrena ${ }^{3}$
}

[1] Centro Nacional de Aceleradores (Universidad de Sevilla, CSIC, JA). Avda. Tomás A. Edison nº 7, E-41092 Sevilla, Spain (phone: +34954460553, e-mail: ymorilla@us.es).

[2] Departament of Física Atómica, Nuclear y Molecular, Universidad de Granada, Avda. De la Fuente Nueva s/n, E-18071 Granada, Spain (e-mail: jpraena@ugr.es).

[3] Departament of Electronic Technology, Universidad Carlos III de Madrid, Avda. Universidad 30, E-28911 Leganés, Madrid, Spain (e-mail: alindoso@ing.uc3m.es)

\begin{abstract}
SUMMARY
The collaborative work in between different public institutions and private companies, through different global projects (RENASER, RENASER+, RENASER3 and RADLAB), has made possible to consolidate the irradiation area in the CNA (Centro Nacional de Aceleradores), with especial emphasis on the testing of devices suitable to be used in aerospace projects. Eight years ago, one of the conclusions in our first project was that using our cyclotron facility it could be possible detecting single events on scales below $250 \mathrm{~nm}$. Along the second project, it was already observed this kind of effects on 130nm devices. Nowadays, the CNA facilities are used to perform irradiation testing in sequential steps with gamma photons and particles, on materials, optoelectronic and microelectronic devices. In the next future, it will be also available to perform thermal cycling tests in combination with radiation, all that simultaneously, and in the same facility of our Centre.
\end{abstract}

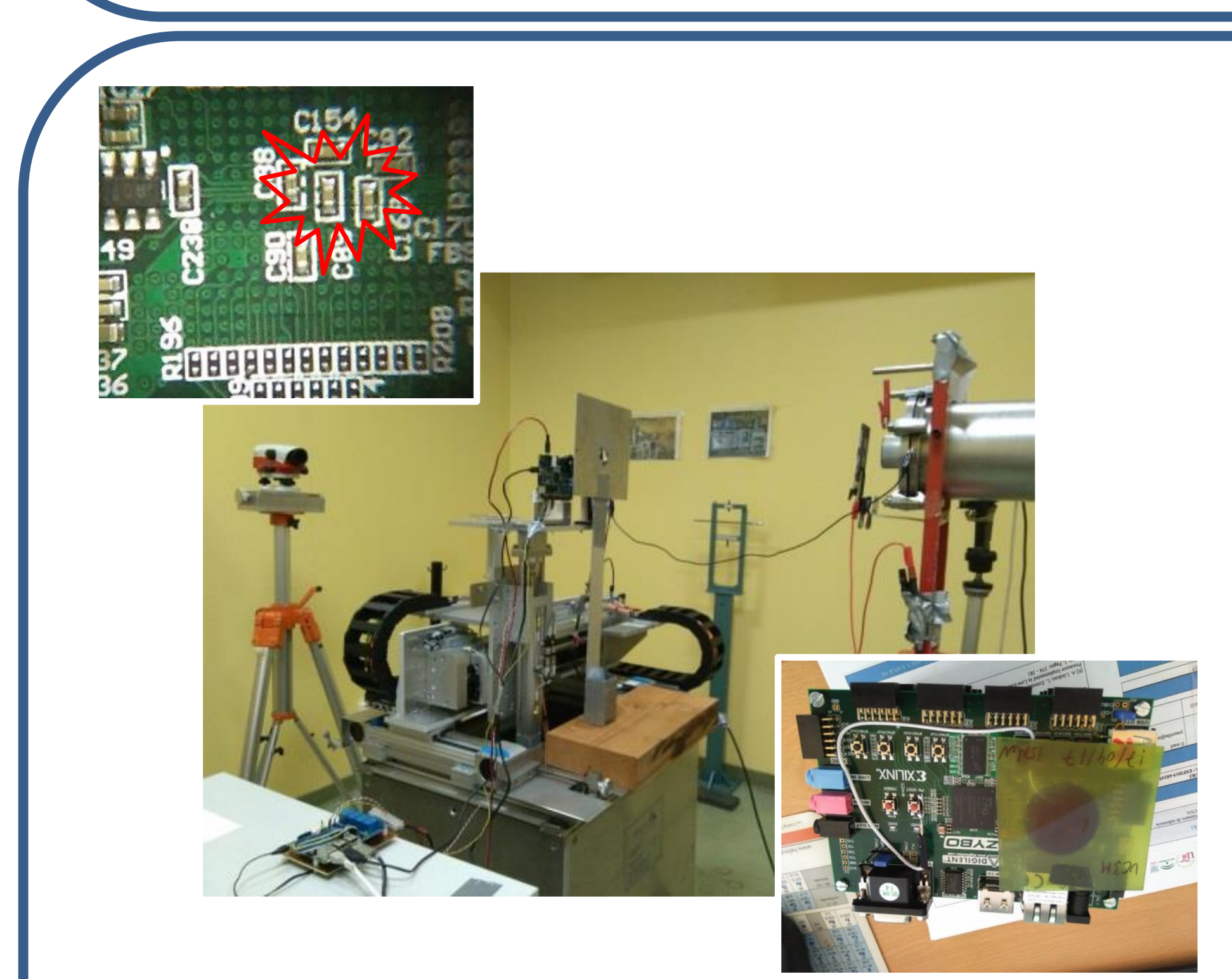

15.0 MeV protons

Exit window: Mylar ${ }^{\circledR} 125 \mu \mathrm{m}$; WDD Air $59 \mathrm{~cm}$ Flux uniformity $>90 \%$ in $15 \mathrm{~mm}$ diameter area Dosimetry by direct current integration SINGULAR EXPERIMENT AT CNA

Proton \& neutron irradiation campaigns on the same device First time in our facility performing both, proton and neutron fault injection campaigns, to evaluate and compare the different robustness achieved in a microprocessor via different models of hardening software.

DUT on Zybo boards, Zynq-7000 FPGA family of Xilinx, $28 \mathrm{~nm}$ technology. ARM A9 microprocessor core with $650 \mathrm{MHz}$ clock frequency.

Benchmark based on Matrix multiplication (MMULT) with an additional circuit PDTC to observe and detect microprocessor errors during execution. $(*)$

\begin{tabular}{|c|c|c|c|c|c|}
\hline Beam & $\begin{array}{c}\text { Flux } \\
\left(\# / \mathbf{s c m}^{\mathbf{2}}\right)\end{array}$ & $\begin{array}{c}\text { Time } \\
\mathbf{( s )}\end{array}$ & $\begin{array}{c}\text { Total } \\
\text { events }\end{array}$ & $\begin{array}{c}\text { Detected } \\
\text { events }\end{array}$ & $\begin{array}{c}\text { Non detected } \\
\text { events }\end{array}$ \\
\hline Protons & $4.3 \cdot 10^{8}$ & 3718 & 311 & $\mathbf{8 5 . 2 \%}$ & $\mathbf{1 4 . 8 \%}$ \\
\hline Neutrons & $1.1 \cdot 10^{6}$ & 27360 & 135 & $\mathbf{8 2 . 2 \%}$ & $\mathbf{1 7 . 8 \%}$ \\
\hline
\end{tabular}

Table. Experimental data on MMULT_32H

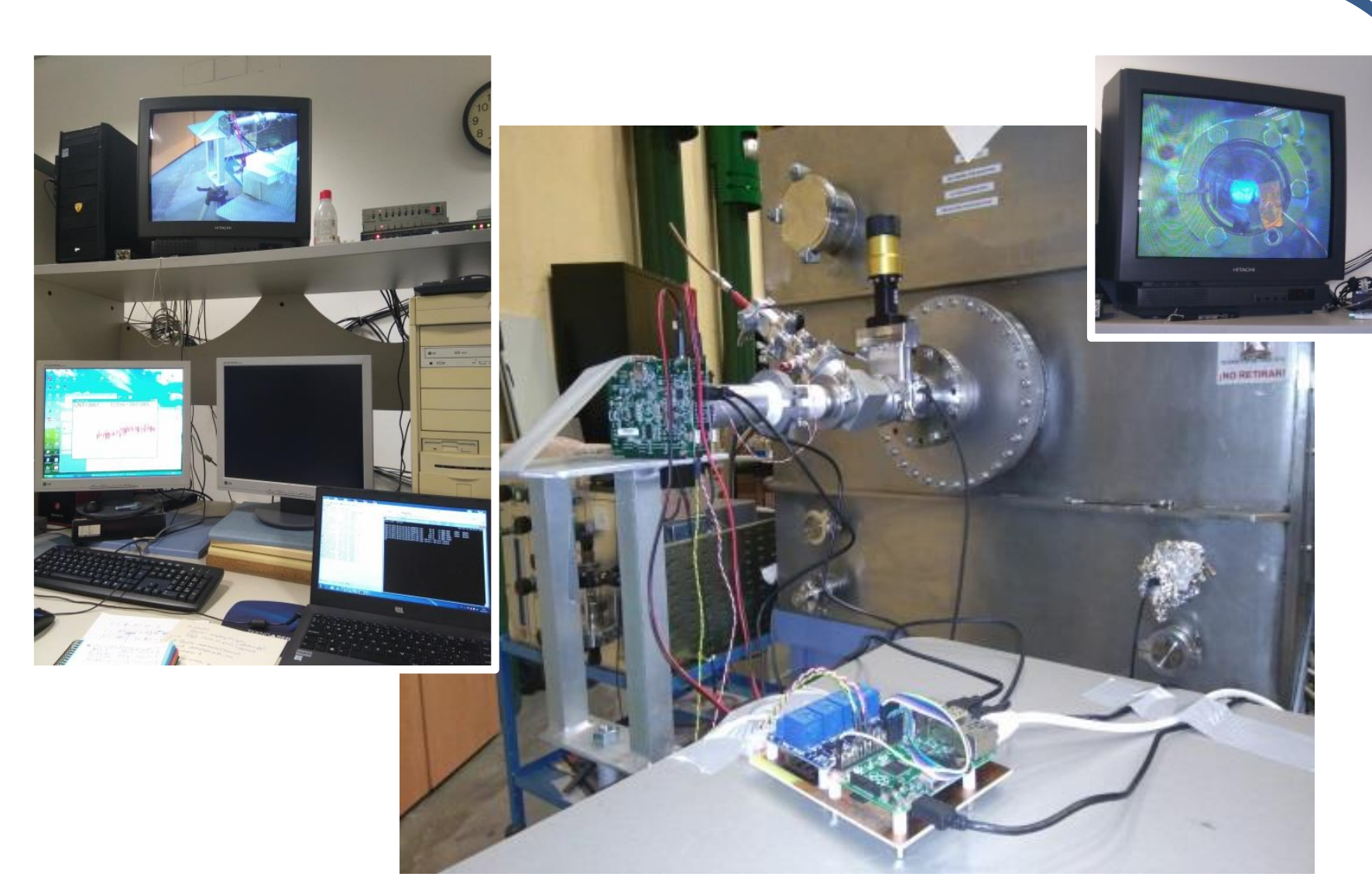

6.1 to $8.6 \mathrm{MeV}$ neutrons

${ }^{2} \mathrm{H}(\mathrm{d}, \mathrm{n}){ }^{3} \mathrm{He}$ Reaction

5.48 MeV deuteron primary beam $10 \mathrm{~mm}$ diameter focusing TD 1 D Air $11 \mathrm{~mm}$; DUT 17mm x 17mm Dosimetry by yield calculation and primary beam monitoring

Deuterated Target:

$500 \mathrm{~g} / \mathrm{cm}^{2}$ thickness, $3 \mathrm{~mm} \mathrm{Al}$ and D/Ti ratio 1.5

${ }^{*}$ ) Visit M. Peña-Fernández et al. in RADECS2018 F session (PF-1)

\section{LABORATORIES AND IRRADIATION ACTIVITY AT CNA}

RADLAB Facility / Co-60 Source

$$
\text { 3MV Tandem Accelerator Laboratory }
$$

Range of dose rate (at July 2018)

0.05 - $240 \mathrm{~Gy}(\mathrm{Si}) / \mathrm{h}$

Flat square irradiation fields

Dose rate uncertainty $\leq 4 \%$

Dosimetry by Farmer ionization chambers

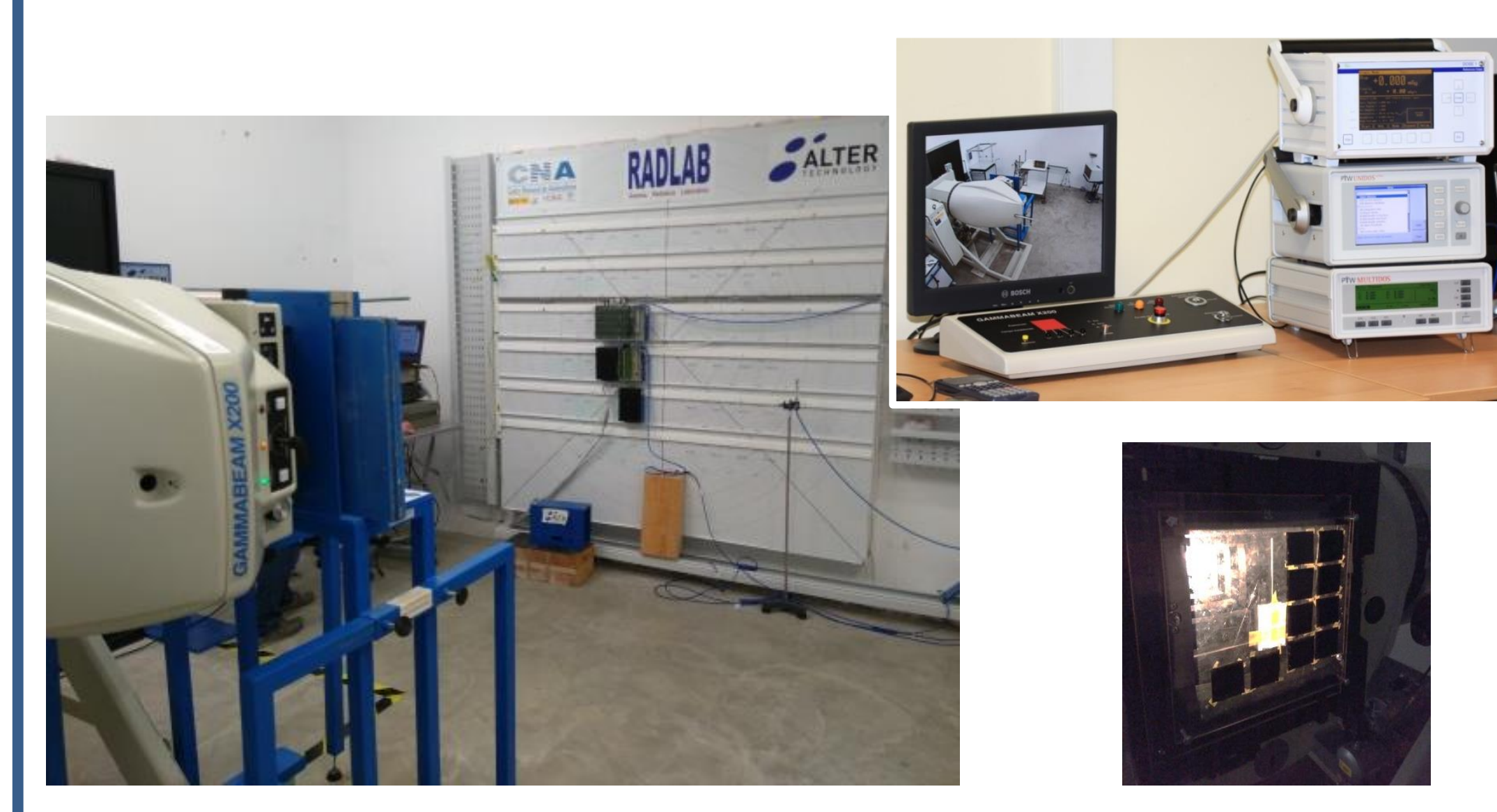

- TID on components and systems (ALTER, UC3M, UV, SOLARMEMS, IMSE...)

- Dosimetry intercomparison exercises

(ALTER, ESA, UCL, UML, JSC-URSC-ISDE)

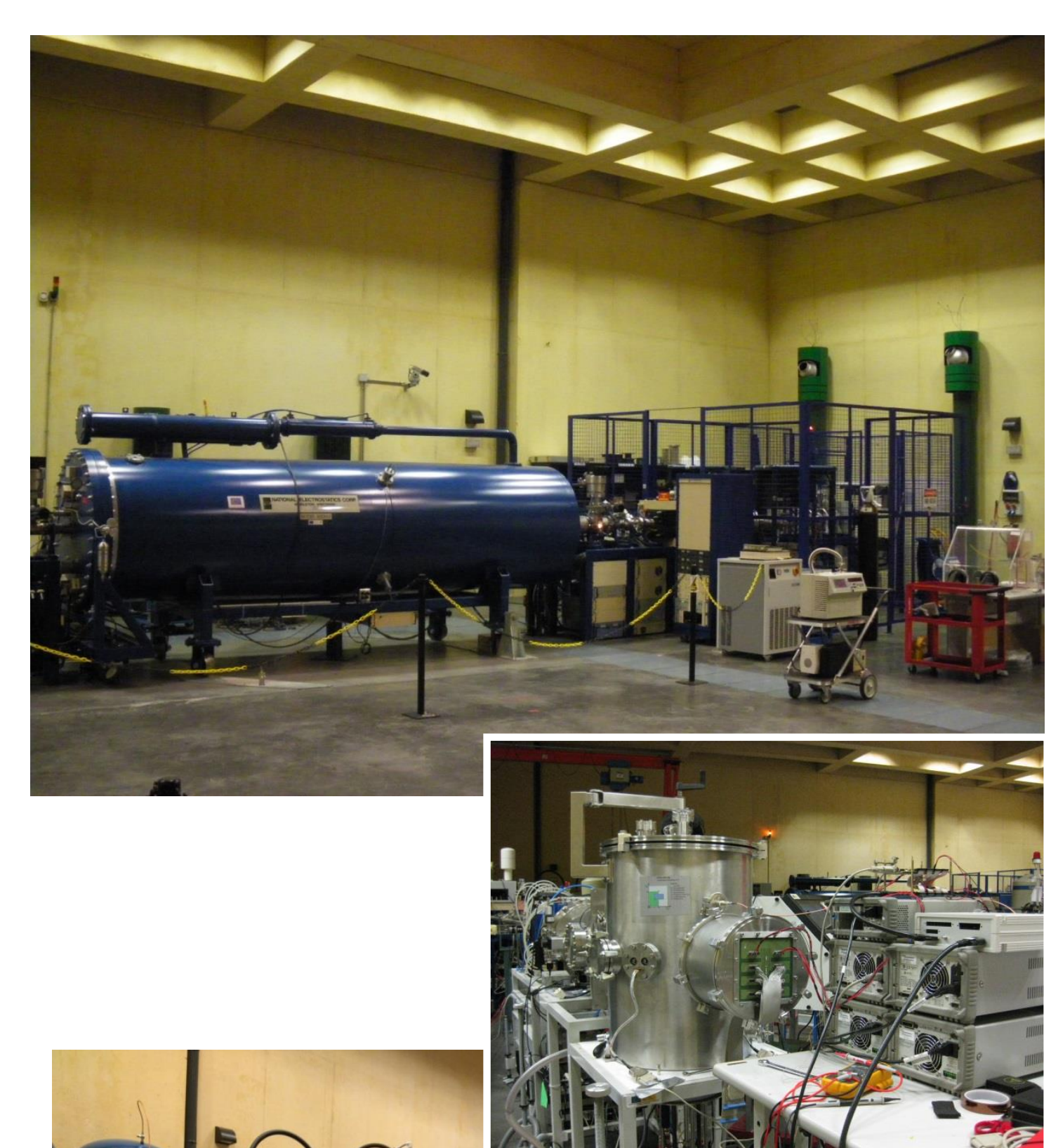

Neutrons and ions working on air and/or vacuum

Tandem (FWHM $0.03 \%$ ) ion beams from $\mathrm{H}$ to $\mathrm{Au}$ (LET < $30 \mathrm{MeV} \cdot \mathrm{cm}^{2} / \mathrm{mg}$ )

Energy range from $600 \mathrm{keV}$ to several $\mathrm{MeV}$ $\left(\mathrm{E}=(1+\mathrm{q}) \mathrm{V}\right.$; e.g. $600 \mathrm{keV}$ to $6 \mathrm{MeV}$ for $\left.\mathrm{H}^{+}\right)$

Maximum irradiation area $17 \mathrm{~cm} \times 20 \mathrm{~cm}$

Energy neutron below $9 \mathrm{MeV}$

${ }^{2} \mathrm{H}(\mathrm{d}, \mathrm{n})$ and ${ }^{7} \mathrm{Li}(\mathrm{p}, \mathrm{n})$ reactions availables

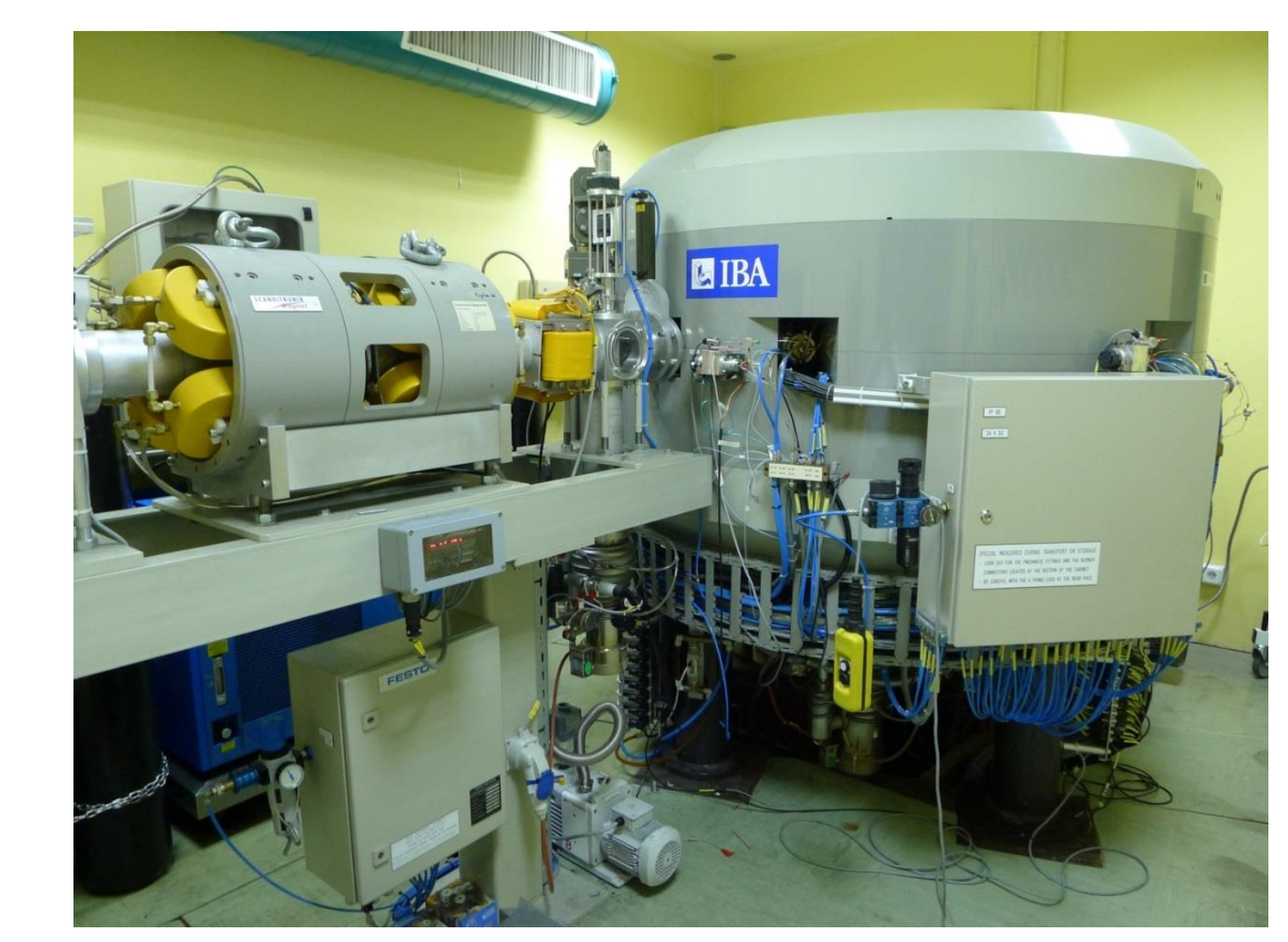

Cyclotron (FWHM 1.1\%) ${ }^{1} \mathrm{H}^{+} 18 \mathrm{MeV}$ and ${ }^{2} \mathrm{H}^{+} 9 \mathrm{MeV}$

Lower energies are available by using foils degraders Uniform irradiation area from 0.5 to $3.5 \mathrm{~cm}$ on diamete

Flux monitoring with current integrator $\left(\approx 10^{8}-10^{11} \mathrm{p} / \mathrm{cm}^{2} \mathrm{~s}\right)$

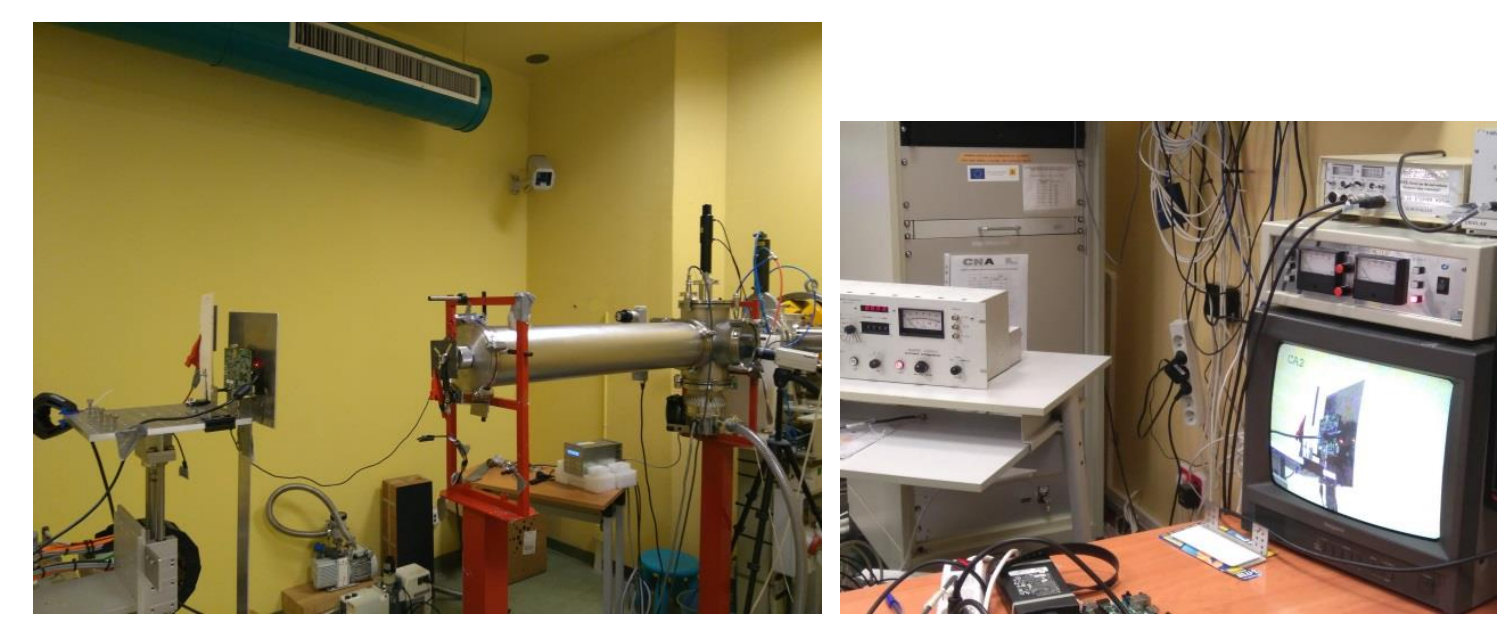

SEU \& DD experiments with low energy particles

$(0.5$ - 6) \& (10 - 18) MeV H; 0.5 MeV D; 8/11 MeV 0; $11 \mathrm{MeV} \mathrm{Al;} \mathrm{6/10} \mathrm{MeV} \mathrm{C}$ (TRAD, ALTER, ARTE, AIRBUS, CESI, SPASOLAB-INTA, UC3M, UA, ETSI-US...)

\section{FACILITY UPDATE IN PROGRESS}

Irradiation at elevated temperature / cryogenic temperature tests will be available; moreover, the possibility to carry out temperature cycles while samples are being irradiated, working in vacuum or another atmosphere.

Operating range: $-80 \circ \mathrm{C}$ to $170^{\circ} \mathrm{C}( \pm 1 \mathrm{\circ} C \mathrm{C})$ with possibility to increase it. Compatible system with all irradiation laboratories (particles and gamma radiation).

Dosimetry systems are currently under study.

\section{Met and next challenges}

It is shown the current capability to perform SEE on devices (highly integrated technologies) at CNA.

The new neutron beam line can provide similar coverage than proton beam at CNA. The fault rate in our experimental conditions, it is good enough for relative comparison studies.

More effort must be done to improve the neutron set-up and the dosimetry methodology for both neutrons and ions irradiation tests. 